\title{
Obtaining and Characterizing Alginate/k-Carrageenan Hydrogel Cross-Linked with Adipic Dihydrazide
}

\author{
Violeta Paşcalău, ${ }^{1}$ Violeta Popescu, ${ }^{1}$ George L. Popescu, ${ }^{1}$ Mircea C. Dudescu, ${ }^{1}$ \\ Gheorghe Borodi, ${ }^{2}$ Adrian M. Dinescu, ${ }^{3}$ and Marioara Moldovan ${ }^{4}$ \\ ${ }^{1}$ Technical University of Cluj-Napoca, Muncii Avenue 103-105, 400641 Cluj-Napoca, Romania \\ ${ }^{2}$ National Institute for Research and Development of Isotopic and Molecular Technologies, Donath Street 65-103, \\ 400293 Cluj-Napoca, Romania \\ ${ }^{3}$ National Institute for Research and Development in Microtechnologies, Erou Iancu Nicolae Street 126 A, \\ 077190 Bucharest, Romania \\ ${ }^{4}$ Babeş-Bolyai University, "Raluca Ripan" Institute for Research in Chemistry, Fântânele Street 30, \\ 400294 Cluj-Napoca, Romania
}

Correspondence should be addressed to Violeta Popescu; violeta.popescu@chem.utcluj.ro

Received 25 May 2013; Accepted 26 September 2013

Academic Editor: Weihua Tang

Copyright (C) 2013 Violeta Paşcalău et al. This is an open access article distributed under the Creative Commons Attribution License, which permits unrestricted use, distribution, and reproduction in any medium, provided the original work is properly cited.

\begin{abstract}
The aim of this paper is obtaining and characterizing hydrogels based on different ratios of oxidized alginate (oA) and k-carrageenan (C), chemically cross-linked with adipic dihydrazide (adh). The alginate (A) was first oxidized with sodium metaperiodate in order to transform it into the dialdehyde derivative, a more reactive compound than alginate. A known procedure for oxidation of alginate with sodium metaperiodate in ethanol-water in order to improve alginate reactivity by transforming the hydroxyl endgroups into dialdehyde was used, preceded by a partially cleavage of the alginate chains. In the second stage, the mixture of dialdehydic derivative of oxidized alginate, $\mathrm{k}$-carrageenan and glycerol subjected to reaction with adipic dihydrazide leads to a SemiInterpenetrated Network covalently cross-linked alginate/k-carrageenan hydrogel $\left(\mathrm{oAC}_{\mathrm{adh}}\right)$, based on the dihydrazone compound which is responsible for the chemical cross-linking. Pure alginate, $\mathrm{k}$-carrageenan, oxidized alginate, adipic dihydrazide and the cross-linked hydrogel were characterized by: FTIR, XRD, and SEM.
\end{abstract}

\section{Introduction}

Our researches related to the development of hydrogels based on natural polysaccharides have focused on finding more biocompatible, nontoxic materials for biomedical applications. We already reported the influence of different alginate $/ \mathrm{k}$ carrageenan ratios on the properties of calcium cross-linked obtained hydrogels [1].

In this work we propose chemically cross-linking of alginate/k-carrageenan hydrogel using adipic dihydrazide and the study of possible synergistic effects on the mechanical properties and swelling behaviour of the obtained hydrogel.

Sodium alginate and k-carrageenan are two polysaccharides of interest, used in drug delivery systems [2,3] due to their biocompatibility, biodegradability, immunogenicity, and nontoxicity [4].
Alginates are naturally derived polysaccharide block copolymers composed of regions of $\beta$-D-mannuronic acid monomers (M-blocks), regions of $\alpha$-L-guluronic acid (Gblocks), and regions of interspersed $M$ and $G$ units $[5,6]$. Alginate is one of the polyuronates, an example of natural ionic polysaccharide forming chain-chain association leading to hydrogels with divalent cations (e.g., $\mathrm{Ca}^{2+}$ ) [7].

Carrageenans are a family of sulphated linear polysaccharides consisting of $(1 \rightarrow 3)$-linked $\beta$-galactose and $(1 \rightarrow 4)$ linked $\alpha$-D-galactose units, which are variously substituted and modified to the 3,6-anhydro derivative, depending on the source and extraction conditions [8]. The units are bound by alternation of $\alpha-1,4$ and $\beta-1,4$ glycosidic linkages. Three main types of carrageenans are known: kappa- $\kappa$, lambda- $\lambda$, and iota- $\iota$, depending on the number and the position of the ionic sulphate groups in the structure of the molecule. 
The presence of a suitable cation, typically potassium, or calcium is an absolute requirement as well for gelation of the carrageenans, especially kappa to proceed [9].

Both alginate and k-carrageenan are polyelectrolytes tending to form physical hydrogels with uni/polyvalent metallic cations. Some authors have reported that alginates can form strong complexes with other natural polyelectrolytes, such as pectin (also a polyuronate) by undergoing chain-chain association and forming hydrogels upon addition of divalent cations (e.g., $\mathrm{Ca}^{2+}$ ) [10], which improve the mechanical and chemical stability of the alginate beads, thus improving the effectiveness of encapsulation [11, 12].

Glycerol was successfully used as plasticizer in other alginate films in order to increase the flexibility [13].

For several applications in which films containing alginate are used, the cross-linking is required [14-16]. Adipic dihydrazide is a well-known cross-linker with reduced toxicity used in chemically cross-linked hydrogels preparation [17].

Bouhadir et al. have oxidized sodium alginate to form low molecular weight oligomers that have been cross-linked with adipic dihydrazide to form alginate hydrogel. They hypothesized that a variety of antineoplastic agents could be locally delivered, alone or in combination, from these hydrogels [18-21].

We also subjected the alginate to the oxidation process with sodium metaperiodate, following a partial oxidation procedure. Subsequently, the partially oxidized alginate, was associated with $\mathrm{k}$-carrageenan and then cross-linked with adipic dihydrazide. The resulted covalently cross-linked alginate/k-carrageenan dual hydrogel has been analyzed by FTIR, XRD, and SEM.

We are interested in obtaining the best formulation of alginate/k-carrageenan hydrogel with improved characteristics required for the potential use in biomedical applications. With respect to the mechanical characteristics and the swelling behaviour evaluation, they were done against the ones of the previous reported ionically cross-linked alginate/k-carrageenan hydrogel film samples. Chemically cross-linked hydrogel samples in the same five formulations were prepared, like the calcium cross-linked ones previously reported [1], of different oxidized alginate: k-carrageenan ratio $(1: 1 ; 1: 2 ; 2: 1 ; 1: 3$, and $3: 1$, resp.) in order to study the influence of hydrogel composition on the mechanical properties and swelling behaviour.

On the other hand the kinetics of swelling has been studied for a series of samples of hydrogels ionically crosslinked with calcium. Details regarding sample preparation and other characteristics have been presented elswere [1].

As far as we know there are no published papers related to this subject.

\section{Materials and Methods}

2.1. Materials. Sodium alginate (A) (ALGOGELTM 6020 from Cargill) and k-carrageenan (C) (AQUAGEL GU-8383 from MARCEL CARRAGEENAN) were kindly provided by KUK-Romania and Enzymes and Derivatives-Romania, respectively. Both are food grade refined products. Sodium metaperiodate (Alfa Aesar USA-Germany) of analytical grade was purchased from Merck. Adipic dihydrazide $97 \%$ (Alfa Aesar GmbH Germany) and ethylene glycol (Fontenay sous Bois France) were provided by the generosity of VWR International GmbH Vienna, Austria. The used glycerol is a commercial product of analytical grade. The utilized water was purified by distillation.

2.2. Partial Oxidation of Alginate. Into a $100 \mathrm{~mL}$ conical glass flask it was introduced $4 \mathrm{~g}$ alginate dispersed in $50 \mathrm{~mL}$ ethanol. A quantity of $2.6 \mathrm{~g}$ sodium periodate solubilised in $40 \mathrm{~mL}$ distilled water was added under magnetic stirring (Stirrer DLS-VELP SCIENTIFICA) (155 rpm), in the dark at room temperature, and kept stirring for $6 \mathrm{~h}$. A volume of $1 \mathrm{~mL}$ of the sample was removed from the reaction mass, diluted with distilled water up to $250 \mathrm{~mL}$ and kept for use in unreacted $\mathrm{IO}_{4}{ }^{-}$determination. Subsequently, $2 \mathrm{~mL}$ of ethylene glycol was added to the reaction mass to consume the excess of sodium periodate, stirred for $30 \mathrm{~min}$, and then filtered, washed with ethanol, and dried at room temperature [22].

2.2.1. Determination of Oxidation Degree by UV-Vis Absorption Spectroscopy. An indicator obtained by mixing equal volumes of KI $20 \%$ and $1 \%$ soluble starch solutions in buffer phosphate at $\mathrm{pH} 7$ was used. A UV-Vis quantitative method using a calibration curve with seven triiodine complex solutions of different concentrations of sodium metaperiodate $\left(0.8554 \cdot 10^{-5} \mathrm{mg} / \mathrm{mL}-3.4216 \cdot 10^{-5} \mathrm{mg} / \mathrm{mL}\right)$ with indicator solution was recorded at $486 \mathrm{~nm}$ using a PerkinElmer Lambda 35 UV-Vis Spectrometer for determination of metaperiodate excess in the alginate oxidative process. In this respect, we took $1 \mathrm{~mL}$ of the solution subjected to the oxidation reaction, before quenching with ethylene glycol, and it was diluted to $250 \mathrm{~mL}$ with distilled water. A sample of $3 \mathrm{~mL}$ from this diluted solution was mixed with $1.5 \mathrm{~mL}$ indicator solution and $0.5 \mathrm{~mL}$ distilled water. The absorbance of triiodine-starch complex formed was measured at $486 \mathrm{~nm}$. The metaperiodate concentration in the sample was determined by measuring the absorbance using the calibration method previously created. The quantity unreacted of metaperiodate reacts with ethylene glycol, transforming the two $\mathrm{OH}$ groups into aldehyde groups [22]. The degree of oxidation (DO, \%) was calculated with the formula: DO\% $=(198 n / m) \times 100$, where $m$ is the weight of sodium alginate $(\mathrm{g}), 198$ is the molecular weight of sodium alginate unit $(\mathrm{g} / \mathrm{mol})$, and $n$ is the consumed amount of substance of periodate (mol) [19].

2.2.2. Preparation of Oxidized Alginate/k-Carrageenan Chemically Cross-Linked Films. Into a flat-bottomed flask equipped with reflux condenser was introduced $3 \mathrm{~g}$ mix in different ratios of partial oxidized alginate (oA) and k-carrageenan (C), according to Table 1 , with $2.5 \mathrm{~g}$ glycerol solubilized in $250 \mathrm{~mL}$ distilled water, under magnetic stirring (Stirrer DLSVelp Scientifica) (1300 rpm). Firstly, the oxidized alginate was introduced in water containing glycerol and heated up to $60^{\circ} \mathrm{C}$ for complete dissolution. Then the corresponding 
TABLE 1: Samples composition: the uncross-linked films $\left(\mathrm{oAC}_{1}, \mathrm{oAC}_{2}, \mathrm{oAC}_{3}, \mathrm{oAC}_{4}\right.$, and $\left.\mathrm{oAC}_{5}\right)$ and the covalently cross-linked films ( $\mathrm{oAC}_{\mathrm{ladh}}$, $\mathrm{oAC}_{2 \mathrm{adh}}, \mathrm{oAC}_{3 \mathrm{adh}}, \mathrm{oAC}_{4 \mathrm{adh}}$, and $\left.\mathrm{oAC}_{5 \mathrm{adh}}\right)$.

\begin{tabular}{lccccc}
\hline Sample & Oxidized alginate $(\mathrm{g})$ & k-Carrageenan $(\mathrm{g})$ & Glycerol $(\mathrm{g})$ & Adipic dihydrazide $(\mathrm{g})$ & Alginate content $(\%)$ \\
\hline $\mathrm{oAC}_{1}$ & 1.5 & 1.5 & 2.5 & 50 \\
$\mathrm{oAC}_{2}$ & 1 & 2 & 2.5 & 33 \\
$\mathrm{oAC}_{3}$ & 2 & 1 & 2.5 & 67 \\
$\mathrm{oAC}_{4}$ & 0.75 & 2,25 & 2.5 & 25 \\
$\mathrm{oAC}_{5}$ & 2.25 & 0.75 & 2.5 & 1.25 & 75 \\
$\mathrm{oAC}_{\text {ladh }}$ & 1.5 & 1.5 & 2.5 & 1.25 & 50 \\
$\mathrm{oAC}_{2 \text { adh }}$ & 1 & 2 & 2.5 & 1.25 & 33 \\
$\mathrm{oAC}_{3 \text { adh }}$ & 2 & 1 & 2.5 & 1.25 & 67 \\
$\mathrm{oAC}_{4 \text { adh }}$ & 0.75 & 2.25 & 2.5 & 1.25 & 25 \\
$\mathrm{oAC}_{5 \text { adh }}$ & 2.25 & 0.75 & 2.5 & & 75 \\
\hline
\end{tabular}

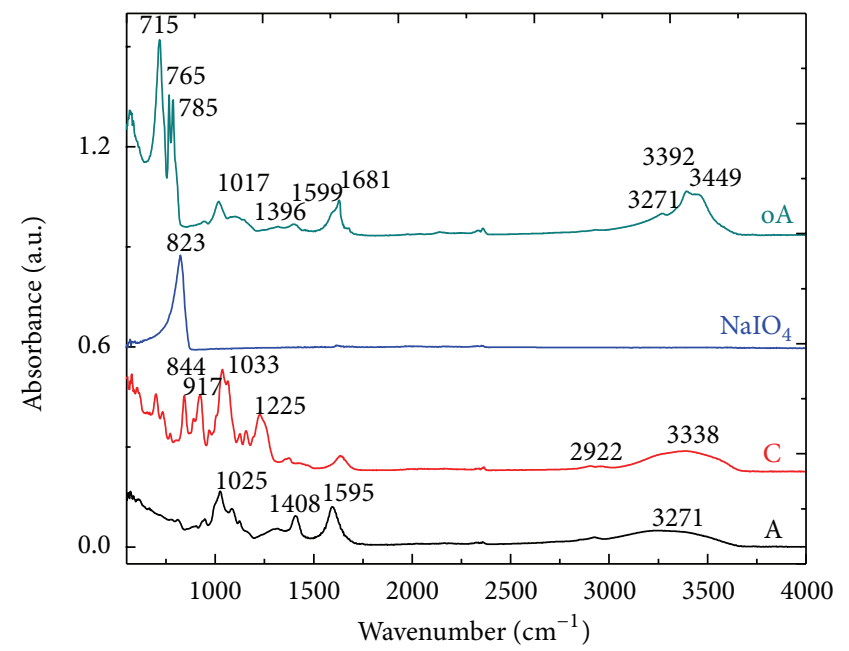

(a)

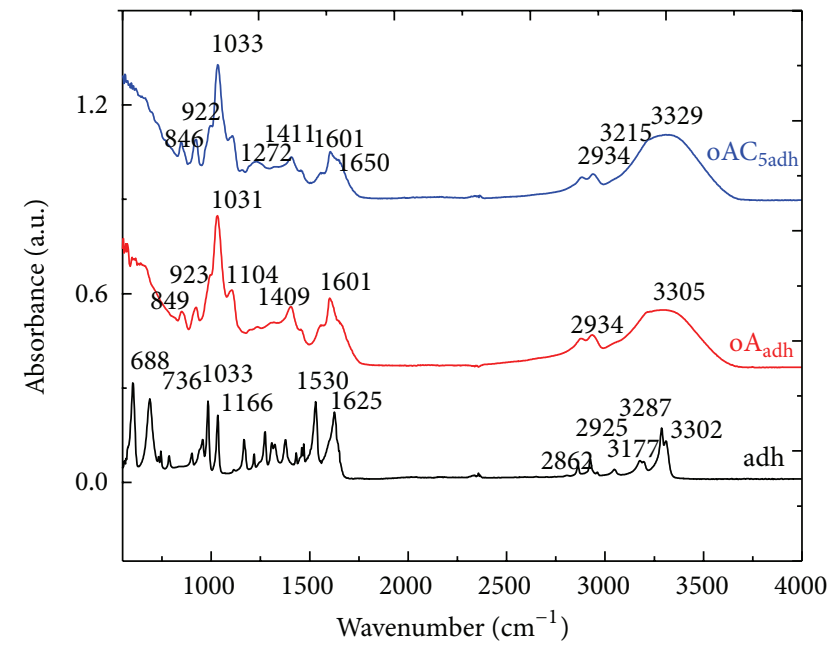

(b)

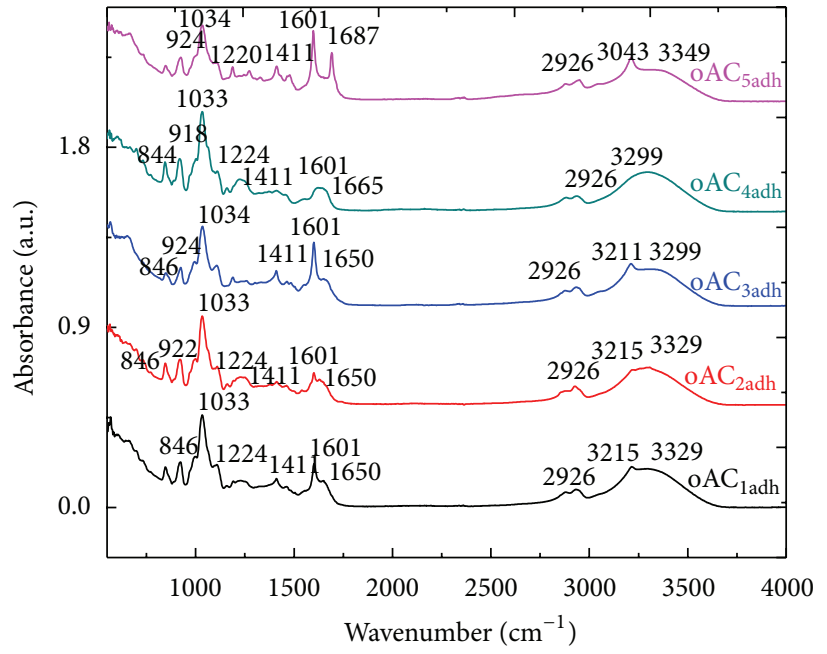

(c)

FIGURE 1: IR spectra of (a) pure alginate (A) and k-carrageenan (C), sodium metaperiodate $\left(\mathrm{NaIO}_{4}\right)$, and oxidized alginate (oA); (b) adipic dihydrazide (adh), hydrogel film of oxidized alginate cross-linked with adipic dihydrazide $\left(\mathrm{oA}_{\mathrm{adh}}\right)$, and cross-linked oxidized alginate/kcarrageenan composite hydrogel film $\left(\mathrm{oAC}_{5 \mathrm{adh}}\right)$; (c) all formulations of cross-linked oxidized alginate/k-carrageenan composite hydrogels films $\left(\mathrm{oAC}_{1 \mathrm{adh}}-\mathrm{oAC}_{5 \mathrm{adh}}\right)$. 


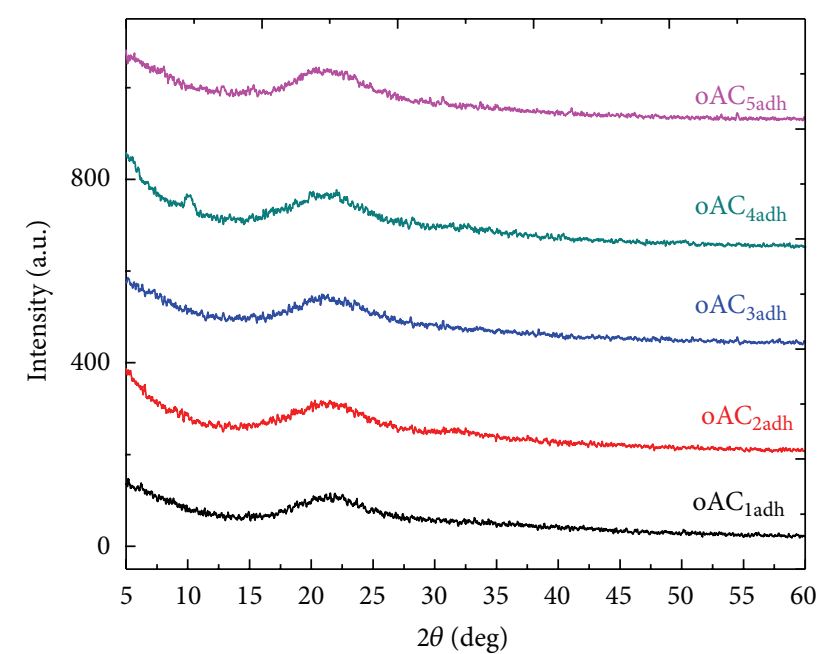

FIGURE 2: XRD patterns of alginate/k-carrageenan hydrogels films chemically cross-linked with adipic dihydrazide $\left(\mathrm{oAC}_{\text {ladh }}{ }^{-}\right.$ $\left.\mathrm{oAC}_{5 \mathrm{adh}}\right)$.

amount of k-carrageenan was added and heated up to $70^{\circ} \mathrm{C}$. A quantity of $1.25 \mathrm{~g}$ of adipic dihydrazide was introduced in the clear solution, and it was kept under continuous stirring and heating at $70^{\circ} \mathrm{C}$ for $1 \mathrm{~h}$. The solution was degassed by sonication for $10 \mathrm{~min}$ (S $30 \mathrm{H}$ Elmasonic), and then it was poured into plastic trays and dried in a convection oven (Memmert) at $40^{\circ} \mathrm{C}$ for about $20 \mathrm{~h}$. A series of uncrosslinked samples containing no adipic dihydrazide was also obtained (samples $\mathrm{oAC}_{1}-\mathrm{OAC}_{5}$ ). The film's composition is reported in Table 1. Homogenous, transparent, and colourless films were obtained with the thickness in the range of microns. The alginate content relative to the total quantity of polysaccharides was expressed.

Both the uncross-linked and the cross-linked films of partially oxidized alginate/k-carrageenan composite films were prepared by casting from aqueous solutions of partially oxidized alginate and k-carrageenan, without cross-linker and with adipic dihydrazide respectively.

2.3. Methods for Oxidized Alginate/k-Carrageenan Hydrogels Characterization. Before being analyzed, the hydrogels film samples were kept at room temperature $\left(23^{\circ} \mathrm{C}\right)$ and humidity in the range of $45-50 \%$.

2.3.1. FTIR Analysis. The composition of oxidized alginate/kcarrageenan hydrogels was confirmed by IR ATR spectra registered on a Spectrum BX PerkinElmer FTIR model equipped with ATR accessory (PIKE MIRacleTM), with diamond crystal plate, in the range of $550-4000 \mathrm{~cm}^{-1}$. The measurements were made on the dried films of hydrogels placed on the diamante window of the ATR, without any other preparation.

2.3.2. XRD Analysis. The X-ray diffraction pattern was obtained using D8 Advance Diffractometer, sealed Cu tube equipped with an incident beam Ge 111 monochromator, $\lambda=1.54056 \AA$. The diffraction data was recorded in the range of $10^{\circ}-70^{\circ}$ with $0.02^{\circ} 2 \theta$ step size, using dried films of hydrogels.

2.3.3. Scanning Electron Microscopy. Scanning electron microscopy was used to characterize the hydrogel films morphology.

The samples were examined using a field emission scanning electron microscope (FE-SEM)-Raith e Line with inlens electron detection capabilities. Since the substrate is an insulator, in order to avoid the electrostatic charging, a thin layer of gold was deposited on the surface of the samples.

\subsection{Study of the Hydrogel Films Characteristics}

2.4.1. Swelling Degree (SD). For the determination of the swelling degree of the cross-linked hydrogels films $\left(\mathrm{oAC}_{1 \mathrm{adh}}{ }^{-}\right.$ $\left.\mathrm{oAC}_{5 \mathrm{adh}}\right)$ we used the tea bag method $[23,24]$. The film samples were weighted (starting mass $-m_{0}$ ), put into a weighed tea bag, sealed, weighed, and immersed in $100 \mathrm{~mL}$ of distilled water under slow stirring $(50 \mathrm{rpm})$ for different periods of time. The swollen gel was allowed to drain by removing the tea bag from the water ( $20 \mathrm{~min})$. The bag was then weighed to determine the weight of the swollen hydrogel $\left(m_{w}\right)$. The swelling degree (SD) is defined by the ratio between the absorbed water mass $\left(m_{w}-m_{0}\right)$ and the starting mass and was calculated using the following equation:

$$
\mathrm{SD}=\frac{m_{w}-m_{0}}{m_{0}}
$$

2.4.2. Swelling Kinetics. For studying the absorbency rate of the hydrogels, the film samples $(0.1 \mathrm{~g})$ were introduced into weighed tea bags and immersed in $100 \mathrm{~mL}$ distilled water under stirring. At successive time periods, the water absorbency of the hydrogels was determined according to the above method.

2.4.3. Mechanical Properties. Mechanical properties of the above described materials were determined by standard tensile tests. All measurements were carried out at room temperature $\left(23^{\circ} \mathrm{C}\right)$ and humidity in the range of $45-50 \%$. The specimens, $0.05-0.15 \mathrm{~mm}$ thick and $20 \mathrm{~mm}$ wide, were loaded to failure with constant crosshead speed $(2 \mathrm{~mm} / \mathrm{min})$ using an Instron $3366(10 \mathrm{KN})$ tensile test machine. Due to the small thickness of the specimens no extensometer could be used, with the engineering strain being calculated based on the crosshead displacement. The gauge length was $80 \mathrm{~mm}$ resulting in nominal strain rates of $4 \cdot 2 \cdot 10^{-4}$. The load was measured with a $10 \mathrm{kN}$ load cell with an accuracy of $0.5 \%$ of indicated load.

\section{Results and Discussion}

3.1. Partial Oxidation of Alginate. Alginate was submitted to a partial oxidation process with sodium metaperiodate in order to transform it into a more reactive derivative which could participate subsequently in a cross-linking reaction 


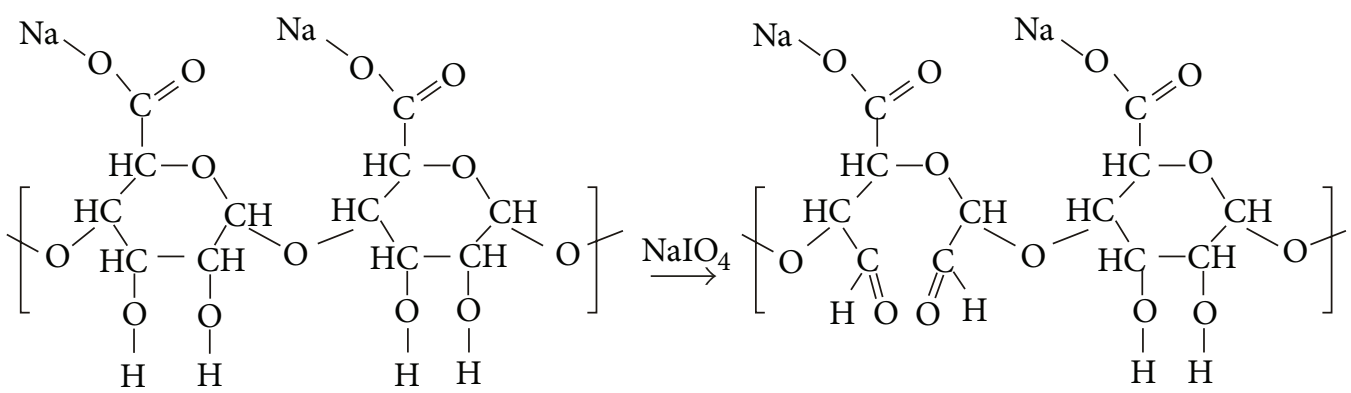

Sodium alginate

Oxidized sodium alginate

SCHEMe 1

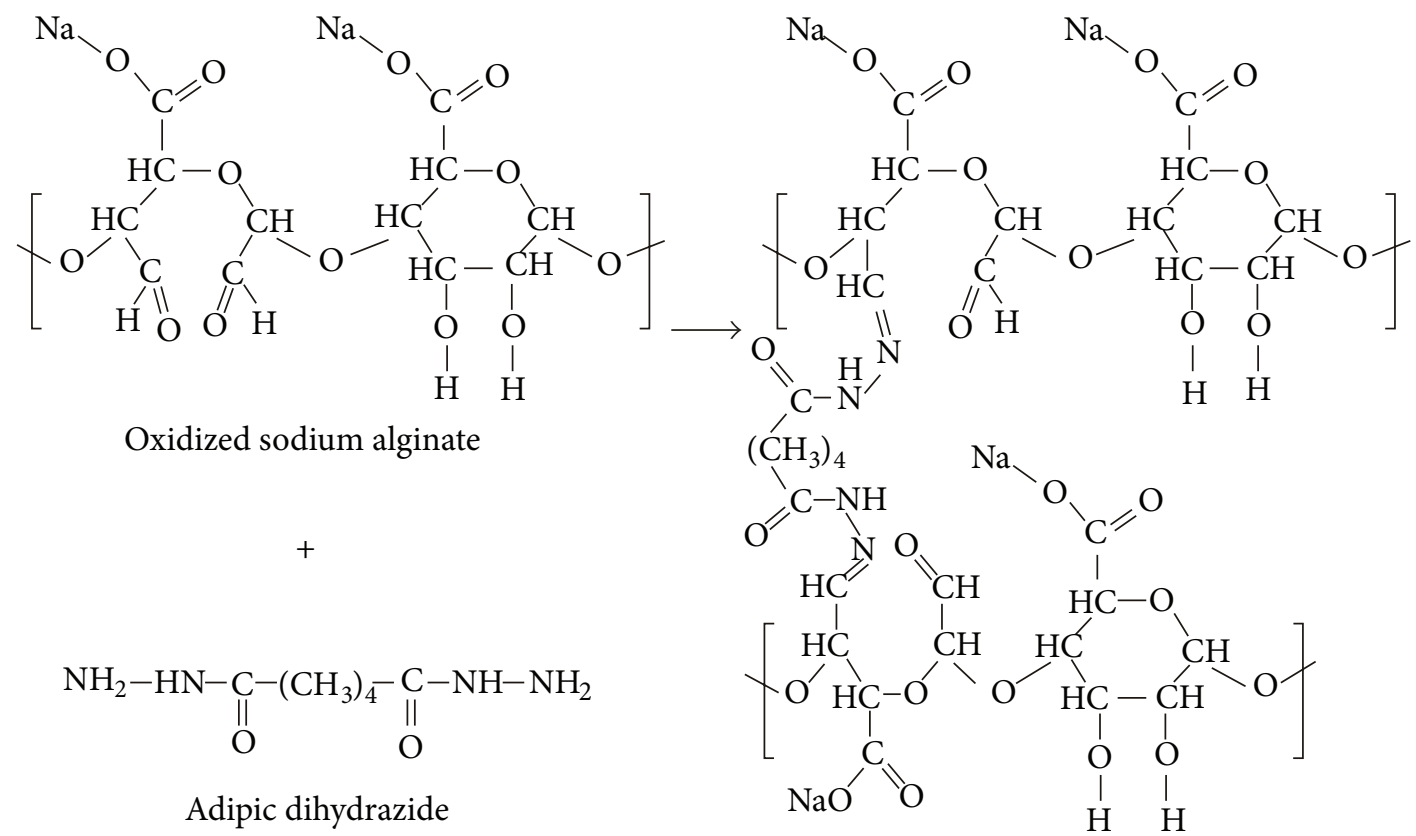

Dihydrazone derivative of oxidized sodium alginate

SCHEME 2

with adipic dihydrazide. As it has been reported [18], the alginate oxidation consists in chain cleavage with oxidizing of some $\mathrm{OH}$ groups and leads to the dialdehyde product (Scheme 1).

The resulted partially oxidized alginate has a different behaviour compared to alginate; losing its solubility in water and as a consequence did not form gel at room temperature, being soluble only by heating up to $56^{\circ} \mathrm{C}$. The decrease of solubility is the result of diminished willing to hydrogen bonds of $\mathrm{OH}$ groups caused by oxidation.

3.2. Determination of Oxidation Degree. The concentration of $\mathrm{IO}_{4}{ }^{-}$in the starting reaction mix was $13.33 \mathrm{mg} / \mathrm{mL}$. After the oxidation process, before the addition of ethylene glycol, the concentration of $\mathrm{IO}_{4}{ }^{-}$determined using UV-Vis quant method is $1.85 \mathrm{mg} / \mathrm{mL}$, corresponding to $86 \%$ sodium metaperiodate consumption. The calculated degree of oxidation is $\mathrm{DO}=51 \%$.
3.3. Oxidized Alginate/k-Carrageenan Chemical Cross-Linked Composite Films Preparation. In order to obtain the cross- linked with adipic dihydrazide alginate/k-carrageenan com- posite hydrogel, we attempted to use the opportunity to make a more reactive derivative than pure alginate by an oxidation process of alginate. It is well known that the dialdehyde product of alginate oxidation can undergo a condensation reaction with adipic dihydrazide [18], leading to a dihydrazone compound, able to cross-link the cleavage chains of oxidized alginate (Scheme 2).
The cross-linking reaction between aldehyde groups of oxidized alginate and the hydrazide groups is characteristic only of oxidized alginate and the addition of k-carrageenan can lead to a Semi-Interpenetrated Network (SemiIPN) of the oxidized alginate/k-carrageenan composite hydrogel. 

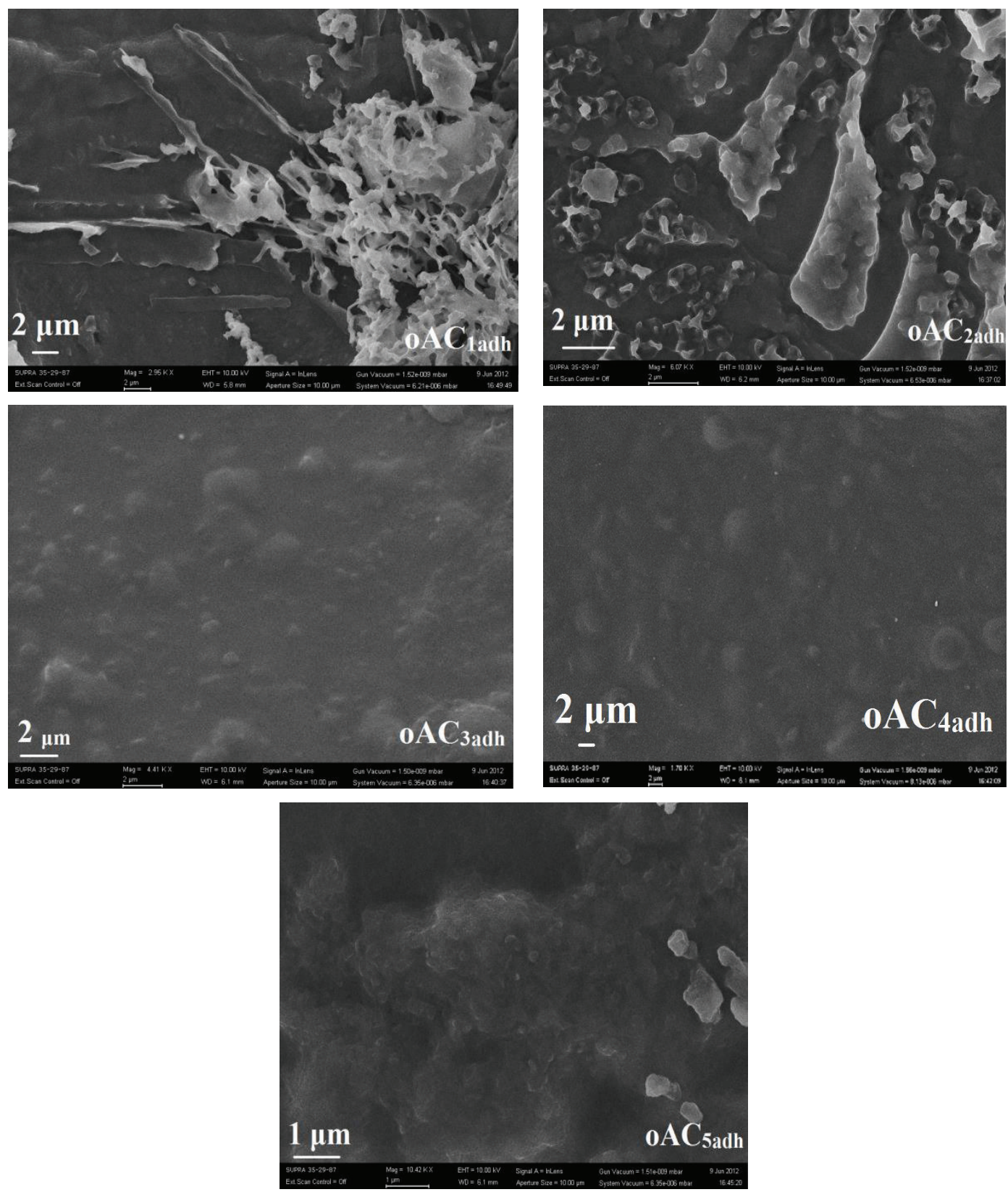

FigurE 3: The SEM images of chemically cross-linked with adipic dihydrazide alginate/k-carrageenan hydrogel films $\left(\mathrm{oAC}_{\text {ladh }}-\mathrm{oAC} \mathrm{C}_{5 \mathrm{adh}}\right)$.

\subsection{The Characterization of the Oxidized Alginate/k-Carrageenan Hydrogel Films}

3.4.1. FTIR Spectra. In the FTIR spectrum of alginate two strong bands at $1600 \mathrm{~cm}^{-1}$ and $1407 \mathrm{~cm}^{-1}$ are attributed to asymmetric and symmetric stretching vibrations of $-\mathrm{COO}^{-}$ groups on the polymer backbone together with the polysaccharides specific bands at $1035-1084 \mathrm{~cm}^{-1}$ of the C-OC (cyclic ether) stretching vibration, the bands at 2928$2932 \mathrm{~cm}^{-1}$ of $\mathrm{C}-\mathrm{H}$ stretching, and a broad band due to the hydrogen bound $\mathrm{OH}$ group appeared between 3200 and $3400 \mathrm{~cm}^{-1}$ attributed to the complex vibrational stretching, associated with free, inter-, and intramolecular bound hydroxyl groups. The characteristic band in the spectrum of $\mathrm{k}$-carrageenan is at $1225 \mathrm{~cm}^{-1}$ due to the $\mathrm{S}=\mathrm{O}$ of sulphate stretch vibration.

The partial oxidation of alginate with sodium metaperiodate can be remarked in the FTIR spectrum. Firstly, there are new bands at $1629 \mathrm{~cm}^{-1}$, characteristic for $\mathrm{C}=\mathrm{O}$ group of the dialdehyde product of the $\mathrm{OH}$ groups oxidation process. Secondly, the bands at $1600 \mathrm{~cm}^{-1}$ and $1407 \mathrm{~cm}^{-1}$ of pure alginate have reduced intensity, especially those characteristics to the $-\mathrm{COO}^{-}$groups $\left(1595 \mathrm{~cm}^{-1}\right.$ and $\left.1411 \mathrm{~cm}^{-1}\right)$. Moreover the $\mathrm{C}-\mathrm{O}-\mathrm{C}$ (cyclic ether) band at $1033 \mathrm{~cm}^{-1}$ is also reduced as a result of the chains cleavage. According to the decrease of the number of $\mathrm{OH}$ groups belonging to alginate through 


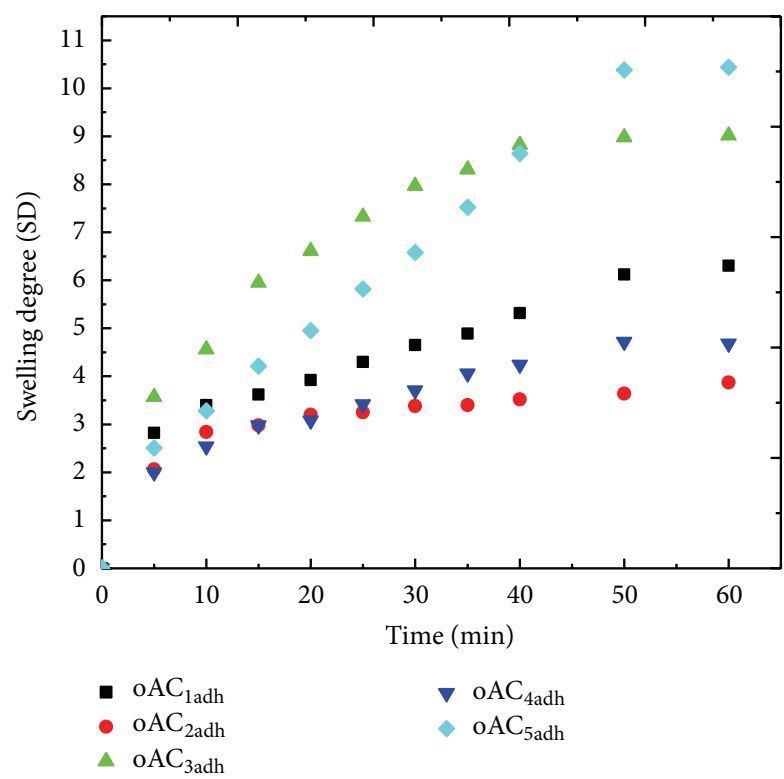

FIGURE 4: Swelling degree of oxidized alginate/k-carrageenan hydrogels $\mathrm{oAC}$ ladh $-\mathrm{OAC}_{5 \mathrm{adh}}$.

oxidation to dialdehyde, the aspect of the broad band between 3200 and $3400 \mathrm{~cm}^{-1}$ looks modified. The intense bands at $715 \mathrm{~cm}^{-1}, 765 \mathrm{~cm}^{-1}$ and $785 \mathrm{~cm}^{-1}$ belong to the $\mathrm{C}-\mathrm{H}$ bonds whose contribution to the cleavage oxidized alginate chains is higher than that in the pure alginate. Another indication on the oxidation process of alginate $\mathrm{OH}$ groups is the intensity decrease of the bands between $2800 \mathrm{~cm}^{-1}$ and $2900 \mathrm{~cm}^{-1}$ due to the $\mathrm{OH}$ vibrations (Figure 1(a)).

In the spectrum of the hydrogel based on oxidized alginate and k-carrageenan, cross-linked with adipic dihydrazide (Figure 1(b)), there are bands derived from oxidized alginate at $3349 \mathrm{~cm}^{-1}, 1691 \mathrm{~cm}^{-1}, 1620 \mathrm{~cm}^{-1}, 1597 \mathrm{~cm}^{-1}$, and $1411 \mathrm{~cm}^{-1}$, from $\mathrm{k}$-carrageenan at $1224 \mathrm{~cm}^{-1}$, and from adipic dihydrazide between $2800-2900 \mathrm{~cm}^{-1}, 1200-1400 \mathrm{~cm}^{-1}$, and $700-800 \mathrm{~cm}^{-1}$. The presence of the characteristic band for the $\mathrm{S}=\mathrm{O}$ of sulphate stretch at $1224 \mathrm{~cm}^{-1}$ in the spectrum of the hydrogel $\mathrm{oAC}_{5 \mathrm{adh}}$ makes the difference between hydrogel of oxidized alginate cross-linked with adipic dihydrazide $\left(\mathrm{oA}_{\mathrm{adh}}\right)$ and the cross-linked oxidized alginate/k-carrageenan hydrogel $\left(\mathrm{oAC}_{5 \text { adh }}\right)$ (Figure $1(\mathrm{~b})$ ). The increase in intensity of the bands attributed to the stretching vibration of the $\mathrm{C}-\mathrm{O}-\mathrm{C}$ (cyclic ether) at $1035-1084 \mathrm{~cm}^{-1}$ and to the $\mathrm{S}=\mathrm{O}$ of a sulphate stretch at $1224 \mathrm{~cm}^{-1}$ reveals the k-carrageenan contribution. Different ratios of oxidized alginate and k-carrageenan in the structure of cross-linked composite hydrogels $\left(\mathrm{oAC}_{1 \mathrm{adh}}{ }^{-}\right.$ $\mathrm{oAC}_{5 \mathrm{adh}}$ ) determine larger or smaller shifts of IR characteristic bands (Figure 1(c)). FTIR spectra of $\mathrm{AC}_{1 \mathrm{adh}}, \mathrm{AC}_{3 \mathrm{adh}}$, and $\mathrm{AC}_{5 \mathrm{adh}}$ show more intense bands at $1650-1690 \mathrm{~cm}^{-1}$, revealing the optimal compositions of hydrogels based on oxidized alginate/k-carrageenan cross-linked with adipic dihydrazide, with higher oxidized alginate content.

3.4.2. X-Ray Diffraction. The diffraction patterns, shown in Figure 2, indicate the amorphous structure of all the analyzed

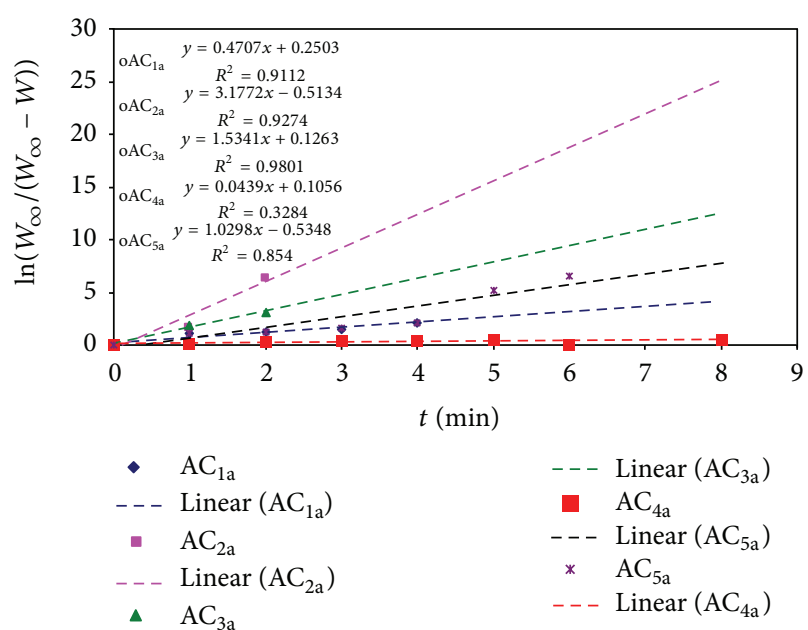

(a)

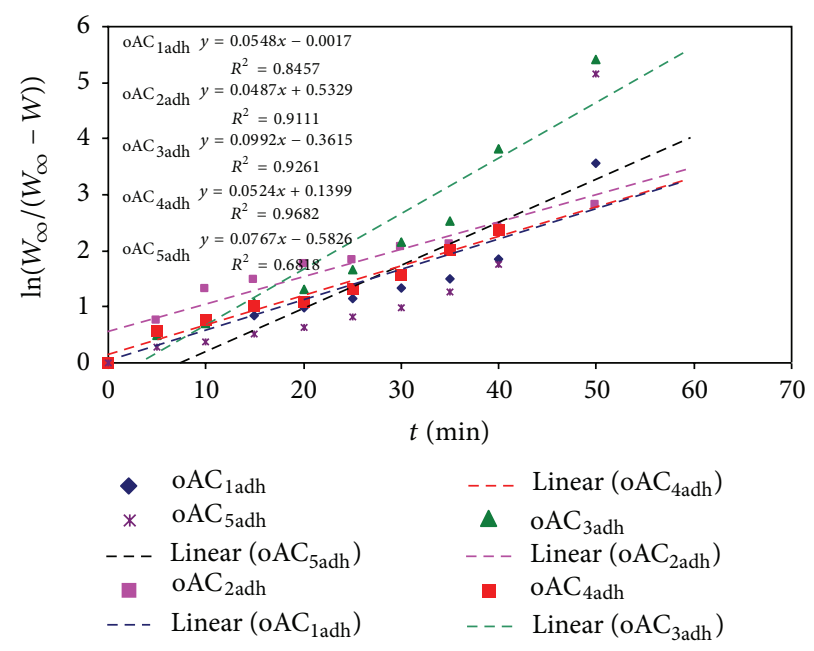

(b)

Figure 5: Plot of $\ln \left(W_{\infty} /\left(W_{\infty}-W_{t}\right)\right)$ against time according to (4) (first order kinetics) for the calcium cross-linked $\left(\mathrm{AC}_{1 \mathrm{a}}-\mathrm{AC}_{5 \mathrm{a}}\right)$ (a) and covalently cross-linked alginate/k-carrageenan hydrogel formulations $\left(\mathrm{oAC}_{1 \mathrm{adh}}-\mathrm{oAC}_{5 \mathrm{adh}}\right)(\mathrm{b})$.

chemically cross-linked hydrogel films, which present halloo at different values of the $2 \theta$ angle in the range $20-25$ of $2 \theta$ degree.

X-ray diffraction patterns put in evidence the necessity of an advanced purification both for the intermediates and the final products, in order to obtain hydrogels of high purity for use in biomedical applications.

$R$, the mean distance between the closest neighbouring chains [25] has been calculated based on the $2 \theta$ values corresponding to the halo (2) (Table 2):

$$
R=\left(\frac{5}{8}\right) \times\left(\frac{\lambda}{\sin \theta}\right)
$$

The more cross-linking points of the hydrogel films formulations with higher content of oxidized alginate, $\mathrm{oAC}_{1 \mathrm{adh}}$, $\mathrm{oAC}_{3 \mathrm{adh}}$, and $\mathrm{oAC}_{5 \mathrm{adh}}$, lead to a more compact structure of hydrogels films, whilst the films with higher k-carrageenan 


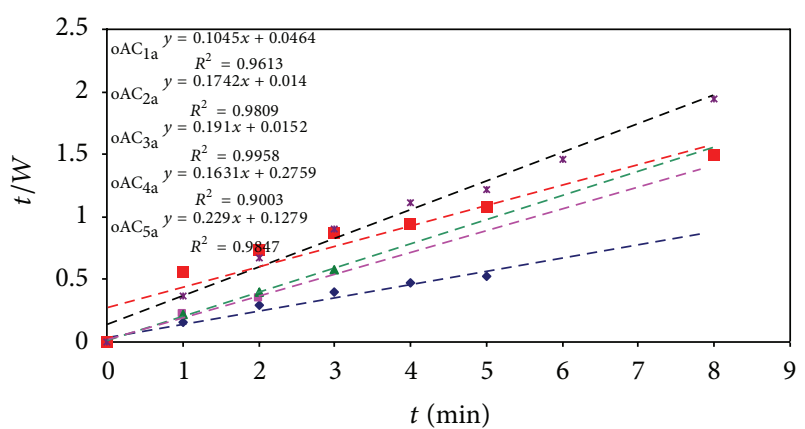

- $\mathrm{AC}_{1 \mathrm{a}}$

- - Linear $\left(\mathrm{AC}_{1 \mathrm{a}}\right)$

- $\mathrm{AC}_{2 \mathrm{a}}$

- - Linear $\left(\mathrm{AC}_{2 \mathrm{a}}\right)$

$\triangle \quad \mathrm{AC}_{3 \mathrm{a}}$

- - Linear $\left(\mathrm{AC}_{3 \mathrm{a}}\right)$

(a)

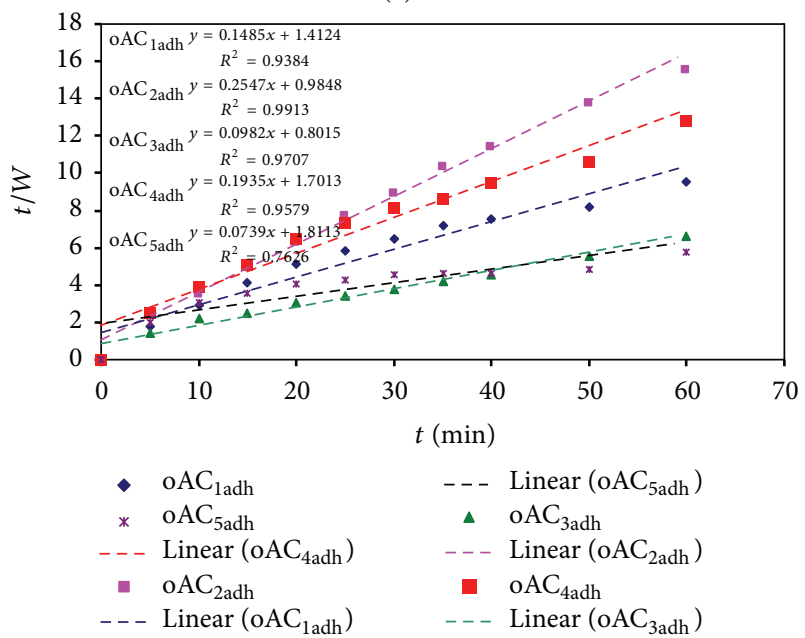

(b)

FIgURE 6: Plot $t / W$ versus time according to (6) (second order kinetics) for the calcium cross-linked $\left(\mathrm{AC}_{1 \mathrm{a}}-\mathrm{AC}_{5 \mathrm{a}}\right)$ (a) and covalently cross-linked alginate/k-carrageenan hydrogel formulations $\left(\mathrm{AC}_{1 \mathrm{adh}}-\mathrm{AC}_{5 \mathrm{adh}}\right)(\mathrm{b})$.

content, $\mathrm{oAC}_{2 \mathrm{adh}}$ and $\mathrm{oAC}_{4 \mathrm{adh}}$, have higher values of the distance between the closest neighbouring chains.

3.4.3. Scanning Electron Microscopy. The morphological characteristics of the chemically cross-linked with adipic dihydrazide alginate/k-carrageenan hydrogel films (Figure 3) look different than the similar hydrogel formulations ionically cross-linked with calcium presented in a previous paper [1]. Some micrographs ( $\mathrm{oAC}_{3 \mathrm{adh}}, \mathrm{oAC}_{4 \mathrm{adh}}$, and $\left.\mathrm{oAC}_{5 \mathrm{adh}}\right)$ present the globular shape of the chemically cross-linked network, similar with the SEM image of the polyguluronic component of alginate (PGA) [26]. As a consequence, it could be said that the polyguluronic blocks from alginate are more susceptible to cleavage followed by oxidation of cleavaged chains and subsequently by chemically crosslinked with adipic dihydrazide. The cross-linking forming the dihydrazone derivative between the oxidized alginate
TABLE 2: The values of the mean distances between the closest neighbouring chains of the hydrogel films cross-linked with adipic dihidrazide $\left(\mathrm{oAC}_{\text {ladh }}-\mathrm{oAC}_{5 \mathrm{adh}}\right)$.

\begin{tabular}{lcc}
\hline Sample & $2 \theta\left(^{\circ}\right)$ & $R(\AA \dot{A})$ \\
\hline $\mathrm{oAC}_{\text {ladh }}$ & 21.43 & 5.1788 \\
$\mathrm{oAC}_{2 \text { adh }}$ & 21.14 & 5.2499 \\
$\mathrm{oAC}_{3 \mathrm{adh}}$ & 21.19 & 5.2372 \\
$\mathrm{oAC}_{4 \text { adh }}$ & 20.93 & 5.3009 \\
$\mathrm{oAC}_{5 \mathrm{adh}}$ & 21.14 & 5.2485 \\
\hline
\end{tabular}

chains is responsible for the regular structure of globular chains. As shown in Figure 3, the SEM micrograph of oAC $\mathrm{Adh}_{1 \mathrm{dh}}$ formulation indicates a porous three-dimensional internal structure of the chemically cross-linked hydrogel.

\subsection{The Study of Hydrogel Films Characteristics}

3.5.1. Swelling Behaviour. The swelling study is relevant to the application of the hydrogels in drug delivery systems, because the hydrogels swelling involves large-scale segmental motion, which ultimately results in increased distances between the polymer chains.

The oxidized alginate/k-carrageenan cross-linked with adipic dihydrazide polymeric network is water resistant, with a moderate swelling degree and a prolonged period before disintegration, confirming the hydrogel structure.

The hydrogel formulations $\left(\mathrm{oAC}_{3 \mathrm{adh}}\right.$ and $\left.\mathrm{oAC}_{5 \mathrm{adh}}\right)$ which alginate content are higher than $\mathrm{AC}_{1 \text { adh }}$ and show an increased swelling degree, while the ones with more $\mathrm{k}$ carrageenan have a relative decreased swelling degree (Figure 4). The higher the content of oxidized alginate is, the more cross-linking points of hydrogel network form and the more cleavaged alginate chains participate in the hydrogel network. It can be concluded that the swelling behaviour of hydrogel depends on the structure of hydrogel network, based on different ratios of oxidized alginate/k-carrageenan.

Comparing to the calcium cross-linked alginate/kcarrageenan hydrogel [1], the chemically cross-linked hydrogel of oxidized alginate/k-carrageenan with adipic dihydrazide showed an decreased swelling degree (SD) because chemical hydrogels have regions of high cross-linking density (low swelling structure) within an otherwise low crosslinking density (high swelling structure) polymeric network. In addition to that, the presence of cleavaged fragments formed by oxidation of alginate chains leads to a modified network size.

Moreover, the cleavage alginate chains make the chemically cross-linked hydrogel more susceptible to the degradation process. It is worth to mention that $\mathrm{oAC}_{2 \mathrm{adh}}$ and $\mathrm{oAC}$ adh hydrogel formulations have an outstanding resistance in water, with a lower value of swelling degree than the others $\mathrm{oAC}_{1 \mathrm{adh}}, \mathrm{oAC}_{3 \mathrm{adh}}$, and $\mathrm{oAC}_{5 \mathrm{adh}}$.

3.5.2. Swelling Kinetics. Some of hydrogels applications require a higher swelling rate as well as a higher swelling capacity. Among the factors influencing the swelling capacity 


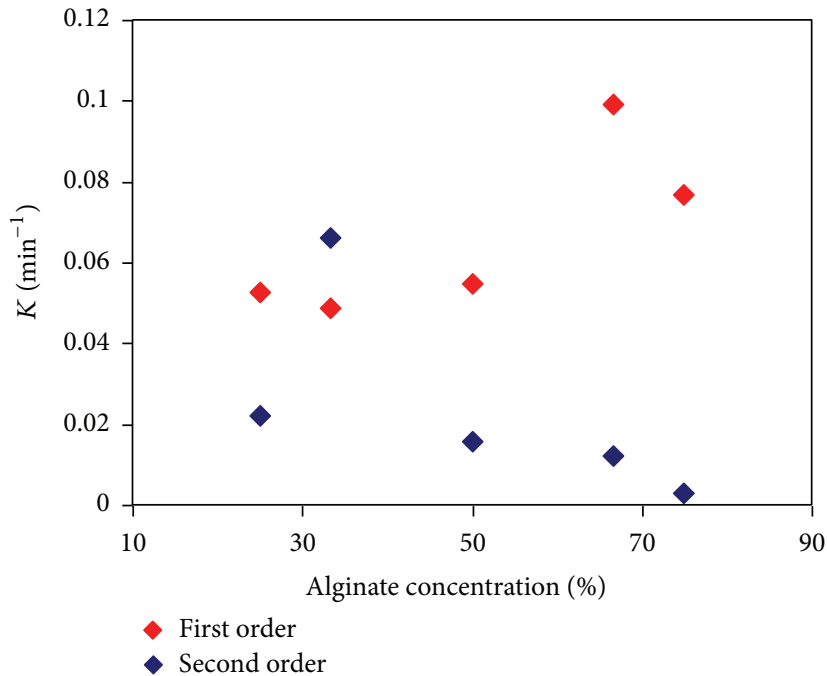

(a)

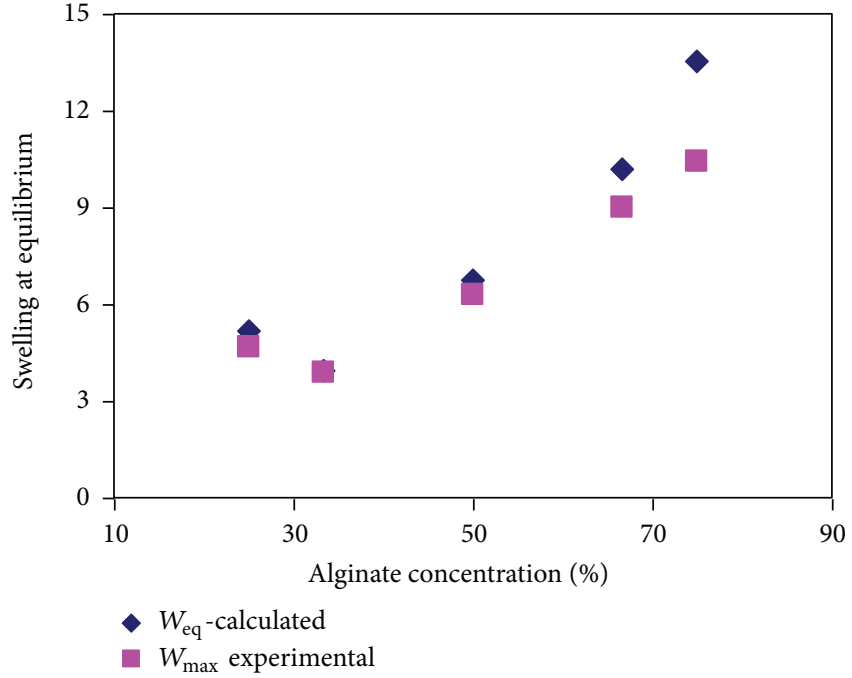

(b)

Figure 7: Plot of (a) swelling rate constant $(K)$ of the first and second order kinetic against the alginate concentration of hydrogel films chemically cross-linked; (b) water content at equilibrium calculated $W_{\text {eq }}$ and experimental determinated $W_{\max }$ against the alginate concentration of hydrogel films chemically cross-linked.

an important one is the composition of polymer network. Thus, the composition of the five covalently cross-linked formulations hydrogels, with $1: 1 ; 1: 2 ; 2: 1 ; 1: 3$; and $3: 1$ alginate:k-carrageenan ratio, could affect the kinetics of water uptake. In order to establish the swelling kinetics of the above hydrogels, the data of the dynamic swelling behavior were fitted with a Voight based equation [27]:

$$
S_{t}=S_{\mathrm{eq}}\left(1-e^{-t / \tau}\right) \text {, }
$$

where $S_{t}$ is swelling at time $t(\mathrm{~g} / \mathrm{g}), S_{\text {eq }}$ is the equilibrium swelling ("power parameter" $(\mathrm{g} / \mathrm{g})$ ), $t$ is time ( $\mathrm{min}$ ) for swelling, and $\tau$ is the "rate parameter." The rate parameter can be determined, using the above formula by plotting $-\ln \left(\left(S_{\mathrm{eq}}-\right.\right.$ $\left.S_{t}\right) / S_{\text {eq }}$ ) against time ( $\left.\mathrm{min}\right)$. The slope of the straight line fitted gives the rate parameter $($ slope $=1 / \tau)$. The $\tau$ value is a measure of swelling rate, in other words a measure of resistance to water permeation; the lower the $\tau$ value, the higher the rate of swelling [28]. The $\tau$ value is time for $S_{\tau}(\mathrm{min})$. The calculated rate parameters for all the hydrogels formulations studied both calcium cross-linked and the chemically are presented in Table 3.

The calcium cross-linked hydrogels have the lowest $\tau$ value so they swell faster than the chemically crosslinked ones, excepting formulation $\mathrm{AC}_{4 \mathrm{ab}}$ with alginate: $\mathrm{k}$ carrageenan ratio $1: 3$.

After the procedure proposed by Quintana et al. [29] for first-order kinetics, the rate of swelling at any time $t$ is directly proportional to the water content that the hydrogel has to obtain before the equilibrium water content $W_{\infty}$ is reached. The swelling is then expressed as

$$
\frac{d W}{d t}=K\left(W_{\infty}-W\right)
$$

TABLE 3: The rate parameter $(\tau)$ of calcium partially $\left(\mathrm{AC}_{\mathrm{la}}-\mathrm{AC}_{5 \mathrm{a}}\right)$ and covalently $\left(\mathrm{oAC}_{\text {ladh }}-\mathrm{oAC}_{5 \mathrm{adh}}\right)$ cross-linked hydrogel samples.

\begin{tabular}{lcc}
\hline Sample & $\begin{array}{c}\text { Fit linear curves equations } \\
\text { Coefficient of determination }\left(R^{2}\right)\end{array}$ & $\begin{array}{c}\text { Rate parameter } \\
(\tau) \pm 10 \%(\mathrm{~min})\end{array}$ \\
\hline $\mathrm{AC}_{1 \mathrm{a}}$ & $y=1.35 x+0.17 ; R^{2}=0.95$ & 0.4 \\
$\mathrm{AC}_{2 \mathrm{a}}$ & $y=0.64 x+0.36 ; R^{2}=1$ & 1.7 \\
$\mathrm{AC}_{3 \mathrm{a}}$ & $y=1.54 x+0.12 ; R^{2}=0.98$ & 0.47 \\
$\mathrm{AC}_{4 \mathrm{a}}$ & $y=0.04 x+0.15 ; R^{2}=0.97$ & 22.71 \\
$\mathrm{AC}_{5 \mathrm{a}}$ & $y=1.03 x-0.53 ; R^{2}=0.85$ & 0.71 \\
$\mathrm{oAC}_{\text {ladh }}$ & $y=0.0548 x-0.002 ; R^{2}=0.85$ & 18.25 \\
$\mathrm{oAC}_{2 \mathrm{adh}}$ & $y=0.0487 x+0.53 ; R^{2}=0.91$ & 20.53 \\
$\mathrm{oAC}_{3 \mathrm{adh}}$ & $y=0.0992 x-0.36 ; R^{2}=0.93$ & 10.08 \\
$\mathrm{oAC}_{4 \mathrm{adh}}$ & $y=0.0524 x+0.14 ; R^{2}=0.97$ & 19.08 \\
$\mathrm{oAC}_{5 \mathrm{adh}}$ & $y=0.0767 x-0.5826 ; R^{2}=0.68$ & 13.04 \\
\hline
\end{tabular}

where $W$ is the water content of the hydrogel at time " $t$ " and $K$ is the proportionality constant between the swelling rate and the unrealized swelling capacity $W_{\infty}-W$.

Upon integration of (4) between the limits $t=0$ to $t$ and $W=0$ to $W$, the following expression is obtained:

$$
\ln \frac{W_{\infty}}{W_{\infty}-W}=K t
$$

If the swelling of the studied hydrogel follows first-order kinetics, the plot of the variation of $\ln \left(W_{\infty} /\left(W_{\infty}-W\right)\right)$ as a function of time should give a straight line. From Figure 5 it can be observed that none of the swelling studies in distilled water followed (5). 


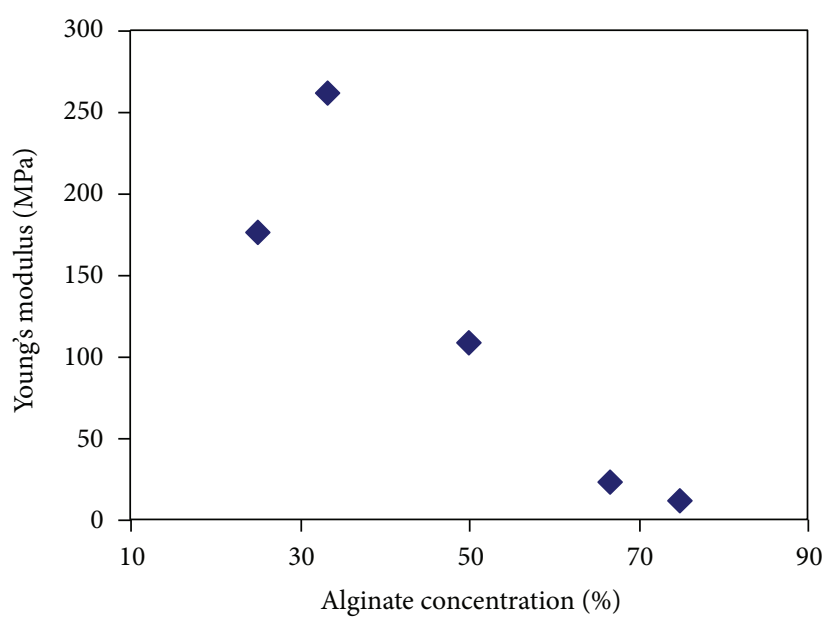

- $E \pm 10 \%(\mathrm{MPa})$

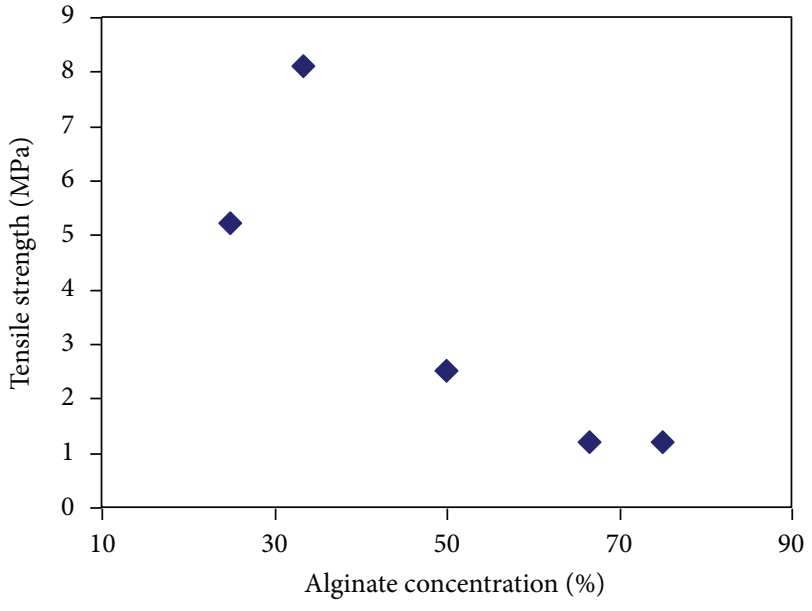

- $\sigma u \pm 10 \%(\mathrm{MPa})$

(a)

(b)

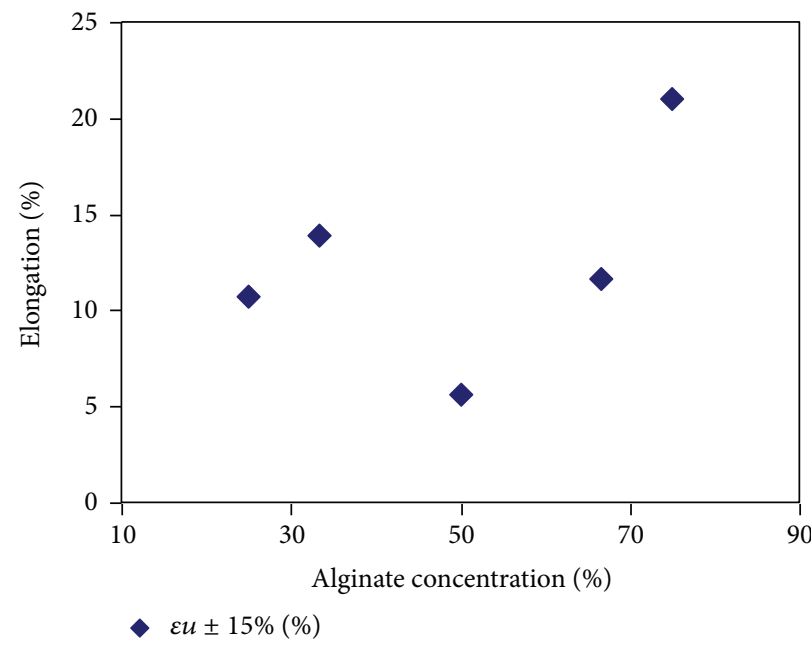

(c)

FIGURE 8: The influence of the alginate concentration of hydrogel films chemically cross-linked on the mechanical properties: Young's modulus (a), tensile strength (b), and elongation at tensile strength (c).

TABLE 4: Mechanical data of hydrogels films partially $\left(\mathrm{AC}_{1 \mathrm{a}}-\mathrm{AC}_{5 \mathrm{a}}\right)$ and complete calcium cross-linked $\left(\mathrm{AC}_{\mathrm{lab}}-\mathrm{AC}_{5 \mathrm{ab}}\right)$ and chemically cross-linked ones $\left(\mathrm{oAC}_{\text {ladh }}-\mathrm{oAC}_{5 \mathrm{adh}}\right)$.

\begin{tabular}{lccc}
\hline Sample & $E \pm 10 \%(\mathrm{MPa})$ & $\sigma_{u} \pm 10 \%(\mathrm{MPa})$ & $\varepsilon_{u} \pm 15 \%(\%)$ \\
\hline $\mathrm{AC}_{\text {la }}$ & 400 & 15 & 19.5 \\
$\mathrm{AC}_{2 \mathrm{a}}$ & 130 & 10 & 32 \\
$\mathrm{AC}_{3 \mathrm{a}}$ & 60 & 12 & 50 \\
$\mathrm{AC}_{4 \mathrm{a}}$ & 460 & 16 & 27.9 \\
$\mathrm{AC}_{5 \mathrm{a}}$ & 190 & 13 & 39.6 \\
$\mathrm{oAC}_{\text {ladh }}$ & 108.5 & 2.5 & 5.6 \\
$\mathrm{oAC}_{2 \mathrm{adh}}$ & 261 & 8.1 & 13.9 \\
$\mathrm{oAC}_{3 \mathrm{adh}}$ & 22.5 & 1.2 & 11.6 \\
$\mathrm{oAC}_{4 \mathrm{adh}}$ & 176 & 5.2 & 10.7 \\
oAC $_{5 \mathrm{adh}}$ & 11.8 & 1.2 & 21 \\
\hline
\end{tabular}

Taking into account second order kinetics, the swelling rate at any time may be written as

$$
\frac{d W}{d t}=K\left(W_{\infty}-W\right)^{2}
$$

After integration of (6) between the limits $t=0$ to $t$ and $W=$ 0 to $W$, the following is obtained

$$
\frac{t}{W}=\frac{1}{K W_{\infty}^{2}}+\frac{1}{W_{\infty}} t .
$$

According to (7), the swelling data must fit a straight line with a slope $1 / W_{\infty}$ and an ordinate intercept $1 / K W_{\infty}^{2}$. The variation of $t / W$ against time for the studied samples is presented in Figure 6. It can be observed that the swelling data give rather straight lines. The swelling behavior of all hydrogels formulations obey second order kinetics. 
The rate constant values $(K)$ confirm a higher rate of swelling process of calcium cross-linked hydrogels versus the chemically cross-linked (Figure 7(a)). Also the swelling process rate is dependent on the alginate: $k$-carrageenan ratio. Both the cross-linker used and the hydrogel composition influence water content at equilibrium $\left(W_{\text {eq }}\right)$ of hydrogel samples (Figure 7(b)).

3.5.3. Mechanical Properties. The measured mechanical data, Young's modulus $(E)$, tensile strength $\left(\sigma_{u}\right)$, and elongation at maximum tensile strength $\left(\varepsilon_{u}\right)$ are presented in Table 4 . For each composition five specimens were tested; the reported data are the mean values.

In comparison with the reported results of partially and complete calcium cross-linked hydrogel films $\left(\mathrm{AC}_{1 \mathrm{a}}-\mathrm{AC}_{5 \mathrm{a}}\right)$ [1], the new compounds have a much lower Young's modulus and ultimate stress, due to the higher content of to some extent cleavage alginate chains, which could make an atypical chemically cross-linked material. A significant increase of the maximum elongation can be noticed (excepting for $\mathrm{oAC}_{5 \mathrm{adh}}$ ). It can be stated that these materials have a pronounced ductile character. The formulations with high k-carrageenan content with $25 \%$ and $33 \%$ alginate, respectively $\left(\mathrm{oAC}_{2 \mathrm{adh}}\right.$ and $\mathrm{oAC}_{4 \mathrm{adh}}$ ), have distinct mechanical properties than those with higher alginate content and low k-carrageenan content $\left(\mathrm{oAC}_{1 \mathrm{adh}}, \mathrm{oAC}_{3 \mathrm{adh}}\right.$, and $\left.\mathrm{oAC}_{5 \mathrm{adh}}\right)$ (Figures $8(\mathrm{a}), 8(\mathrm{~b})$, and $8(\mathrm{c}))$.

\section{Conclusions}

In this work we synthesized five formulations of oxidized alginate/k-carrageenan dual hydrogel films, using glycerol as plasticizer and adipic dihydrazide as cross-linker.

In the beginning we subjected alginate to an oxidation process with sodium metaperiodate to obtain the dialdehyde product of alginate, the oxidized alginate (oA), capable to react with adipic dihydrazide into a cross-linking reaction.

Different ratios of oxidized alginate and k-carrageenan together with adipic dihydrazide were used to prepare five formulations of chemically cross-linked hydrogels $\left(\mathrm{oAC}_{1 \mathrm{adh}}{ }^{-}\right.$ $\left.\mathrm{oAC}_{5 \mathrm{adh}}\right)$.

The structure of the new hydrogels was characterized by FTIR, XRD, and SEM.

The optimal formulations recommended for chemically cross-linked with adipic dihydrazide are those with $1: 2$ $\left(\mathrm{oAC}_{2 \mathrm{adh}}\right)$ and $1: 3\left(\mathrm{oAC}_{4 \mathrm{adh}}\right)$ ratio of alginate $\mathrm{k}$-carrageenan, which are highly water resistant in the swollen form.

It is worth to mention that all formulations of chemically cross-linked hydrogels $\left(\mathrm{oAC}_{1 \mathrm{adh}}-\mathrm{oAC}_{5 \mathrm{adh}}\right)$ films are water resistant, an indispensable characteristic which defines a hydrogel formation.

Comparing to the calcium cross-linked hydrogel films of alginate/k-carrageenan, the achieved chemically cross-linked hydrogel films show better mechanical properties having a pronounced ductile character.

The SEM images of the chemically cross-linked hydrogel formulations look different from the calcium cross-linked ones, according to their different structures, such as modified cleavage alginate chains and the new created covalent bonds.

Regarding the swelling behaviour, the new formulations are more susceptible to disintegration than the calcium crosslinked ones, due to the appearance of cleavage chains through the oxidation reaction of alginate.

The swelling kinetics were also investigated. The rate parameter $(\tau)$ and the constant rate $(K)$ reveal the smaller swelling rate of covalently cross-linked hydrogels than those calcium cross-linked.

The XRD patterns of the chemically cross-linked hydrogel formulations put in evidence the amorphous structure of all the studied samples and small differences between samples depending on the alginate: $\mathrm{k}$-carrageenan ratio. The explanation consists in the fact that the number of cross-linking points does not depend on the k-carrageenan contribution.

We will continue to study the swelling behaviour of these hydrogels in solutions with varied $\mathrm{pH}$ in order to establish the potential use in biological applications. Subsequently these hydrogels will be loaded with a drug and then will be subjected to release the loaded drug in different simulated body fluids and the study's results will be reported in the next papers.

\section{Acknowledgments}

This paper was supported by the project "Improvement of the doctoral studies quality in engineering science for development of the knowledge based society-QDOC" Contract no. POS-DRU/107/1.5/S/78534, project cofunded by the European Social Fund through the Sectorial Operational Program Human Resources 2007-2013; Contract PN2 165/2012, project funded by the Romanian Ministry of Education and Research, National Project PNII no. 65/2012.

\section{References}

[1] V. Paşcalău, V. Popescu, G. L. Popescu et al., "The alginate/kcarrageenan ratio's influence on the properties of the crosslinked composite films," Journal of Alloys and Compounds, vol. 536, supplement 1, pp. S418-S423, 2012.

[2] S. Hua, H. Ma, X. Li, H. Yang, and A. Wang, "pH-sensitive sodium alginate/poly(vinyl alcohol) hydrogel beads prepared by combined $\mathrm{Ca}^{2+}$ crosslinking and freeze-thawing cycles for controlled release of diclofenac sodium," International Journal of Biological Macromolecules, vol. 46, no. 5, pp. 517-523, 2010.

[3] M. G. Sankalia, R. C. Mashru, J. M. Sankalia, and V. B. Sutariya, "Stability improvement of alpha-amylase entrapped in kappa-carrageenan beads: physicochemical characterization and optimization using composite index," International Journal of Pharmaceutics, vol. 312, no. 1-2, pp. 1-14, 2006.

[4] M. George and T. E. Abraham, "Polyionic hydrocolloids for the intestinal delivery of protein drugs: alginate and chitosan-a review," Journal of Controlled Release, vol. 114, no. 1, pp. 1-14, 2006.

[5] H. Akhondi, E. Taheri-Nassaj, and A. Taavoni-Gilan, "Gelcasting of alumina-zirconia-yttria nanocomposites with $\mathrm{Na}$ alginate system," Journal of Alloys and Compounds, vol. 484, no. 1-2, pp. 452-457, 2009. 
[6] X. Liu, L. Qian, T. Shu, and Z. Tong, "Rheology characterization of sol-gel transition in aqueous alginate solutions induced by calcium cations through in situ release," Polymer, vol. 44, no. 2, pp. 407-412, 2002.

[7] Y. Fang, S. Al-Assaf, G. O. Phillips, K. Nishinari, T. Funami, and P. A. Williams, "Binding behavior of calcium to polyuronates: comparison of pectin with alginate," Carbohydrate Polymers, vol. 72, no. 2, pp. 334-341, 2008.

[8] C. H. Tang, H. Wu, Z. Chen, and X. Q. Yang, "Formation and properties of glycinin-rich and $\beta$-conglycinin-rich soy protein isolate gels induced by microbial transglutaminase," International Food Research Journal, vol. 39, no. 1, pp. 87-97, 2006.

[9] V. L. Campo, D. F. KaWano, D. B. da Silva J, and I. Carvalho, "Carrageenans: biological properties, chemical modifications and structural analysis-a review," Carbohydrate Polymers, vol. 77, no. 2, pp. 167-180, 2009.

[10] V. Pillay and R. Fassihi, "In vitro release modulation from crosslinked pellets for site-specific drug delivery to the gastrointestinal tract. I. Comparison of $\mathrm{pH}$-responsive drug release and associated kinetics," Journal of Controlled Release, vol. 59, no. 2, pp. 229-242, 1999.

[11] V. Pillay and R. Fassihi, "In vitro release modulation from crosslinked pellets for site-specific drug delivery to the gastrointestinal tract. II. Physicochemical characterization of calciumalginate, calcium-pectinate and calcium-alginate-pectinate pellets," Journal of Controlled Release, vol. 59, no. 2, pp. 243-256, 1999.

[12] C. P. Hung, H. F. Lo, W. H. Hsu, S. C. Chen, and L. L. Lin, "Immobilization of escherichia coli novablue gamma-glutamyltranspeptidase in Ca-alginate-kappa-carrageenan beads," Applied Biochemistry and Biotechnology, vol. 150, no. 2, pp. 157170, 2008.

[13] M. A. da Silva, A. C. K. Bierhalz, and T. G. Kieckbusch, "Alginate and pectin composite films crosslinked with $\mathrm{Ca}^{2+}$ ions: effect of the plasticizer concentration," Carbohydrate Polymers, vol. 77, no. 4, pp. 736-742, 2009.

[14] O. Smidsrød, "Molecular basis for some physical properties of alginates in the gel state," Faraday Discussions of the Chemical Society, vol. 57, pp. 263-274, 1974.

[15] I. Braccini and S. Pérez, "Molecular basis of $\mathrm{Ca}^{2+}$-induced gelation in alginates and pectins: the egg-box model revisited," Biomacromolecules, vol. 2, no. 4, pp. 1089-1096, 2001.

[16] W. E. Hennink and C. F. Van Nostrum, "Novel crosslinking methods to design hydrogels," Advanced Drug Delivery Reviews, vol. 54, no. 1, pp. 13-36, 2002.

[17] W. E. Hennink, S. J. De Jong, G. W. Bos, T. F. J. Veldhuis, and C. F. van Nostrum, "Biodegradable dextran hydrogels crosslinked by stereocomplex formation for the controlled release of pharmaceutical proteins," International Journal of Pharmaceutics, vol. 277, no. 1-2, pp. 99-104, 2004.

[18] K. H. Bouhadir, E. Alsberg, and D. J. Mooney, "Hydrogels for combination delivery of antineoplastic agents," Biomaterials, vol. 22, no. 19, pp. 2625-2633, 2001.

[19] C. Gao, M. Liu, S. Chen, S. Jin, and J. Chen, "Preparation of oxidized sodium alginate-graft-poly((2-dimethylamino) ethyl methacrylate) gel beads and in vitro controlled release behavior of BSA," International Journal of Pharmaceutics, vol. 371, no. 1-2, pp. 16-24, 2009.
[20] B. Balakrishnan, S. Lesieur, D. Labare, and A. Jayakrishnan, "Periodate oxidation of sodium alginate in water and in ethanolwater mixture: a comparative study," Carbohydrate Research, vol. 340, no. 7, pp. 1425-1429, 2005.

[21] N. Q. Wu, C. Y. Pan, B. J. Zhang, Y. P. Rao, and D. Yu, "Preparation and properties of a thermo-sensitive hydrogel based on oxidized sodium alginate," Acta Polymerica Sinica, vol. 6, pp. 497-502, 2007.

[22] C. G. Gomez, M. Rinaudo, and M. A. Villar, "Oxidation of sodium alginate and characterization of the oxidized derivatives," Carbohydrate Polymers, vol. 67, no. 3, pp. 296-304, 2007.

[23] A. Pourjavadi and G. R. Mahdavinia, "Superabsorbency, pH-sensitivity and swelling kinetics of partially hydrolyzed chitosan-g-poly(acrylamide) hydrogels," Turkish Journal of Chemistry, vol. 30, no. 5, pp. 595-608, 2006.

[24] J. B. Xu, J. P. Bartley, and R. A. Johnson, "Preparation and characterization of alginate-carrageenan hydrogel films crosslinked using a water-soluble carbodiimide (WSC)," Journal of Membrane Science, vol. 218, no. 1-2, pp. 131-146, 2003.

[25] H. P. Klug and L. L. Alexander, X-Ray Diffraction Procedures, John Wiley \& Sons, New York, NY, USA, 1974.

[26] M. Chhatbar, R. Meena, K. Prasad, and A. K. Siddhanta, "Microwave assisted rapid method for hydrolysis of sodium alginate for M/G ratio determination," Carbohydrate Polymers, vol. 76, no. 4, pp. 650-656, 2009.

[27] K. M. Aiedeh, M. O. Taha, Y. Al-Hiari, Y. Bustanji, and H. S. Alkhatib, "Effect of ionic crosslinking on the drug release properties of chitosan diacetate matrices," Journal of Pharmaceutical Sciences, vol. 96, no. 1, pp. 38-43, 2007.

[28] A. Pourjavadi and G. R. Mahdavinia, "Superabsorbency, $\mathrm{pH}$-sensitivity and swelling kinetics of partially hydrolyzed chitosan-g-poly(acrylamide) hydrogels," Turkish Journal of Chemistry, vol. 30, no. 5, pp. 595-608, 2006.

[29] J. R. Quintana, N. E. Valderruten, and I. Katime, "Synthesis and swelling kinetics of poly(dimethylaminoethyl acrylate methyl chloride quaternary-co-itaconic acid) hydrogels," Langmuir, vol. 15, no. 14, pp. 4728-4730, 1999. 

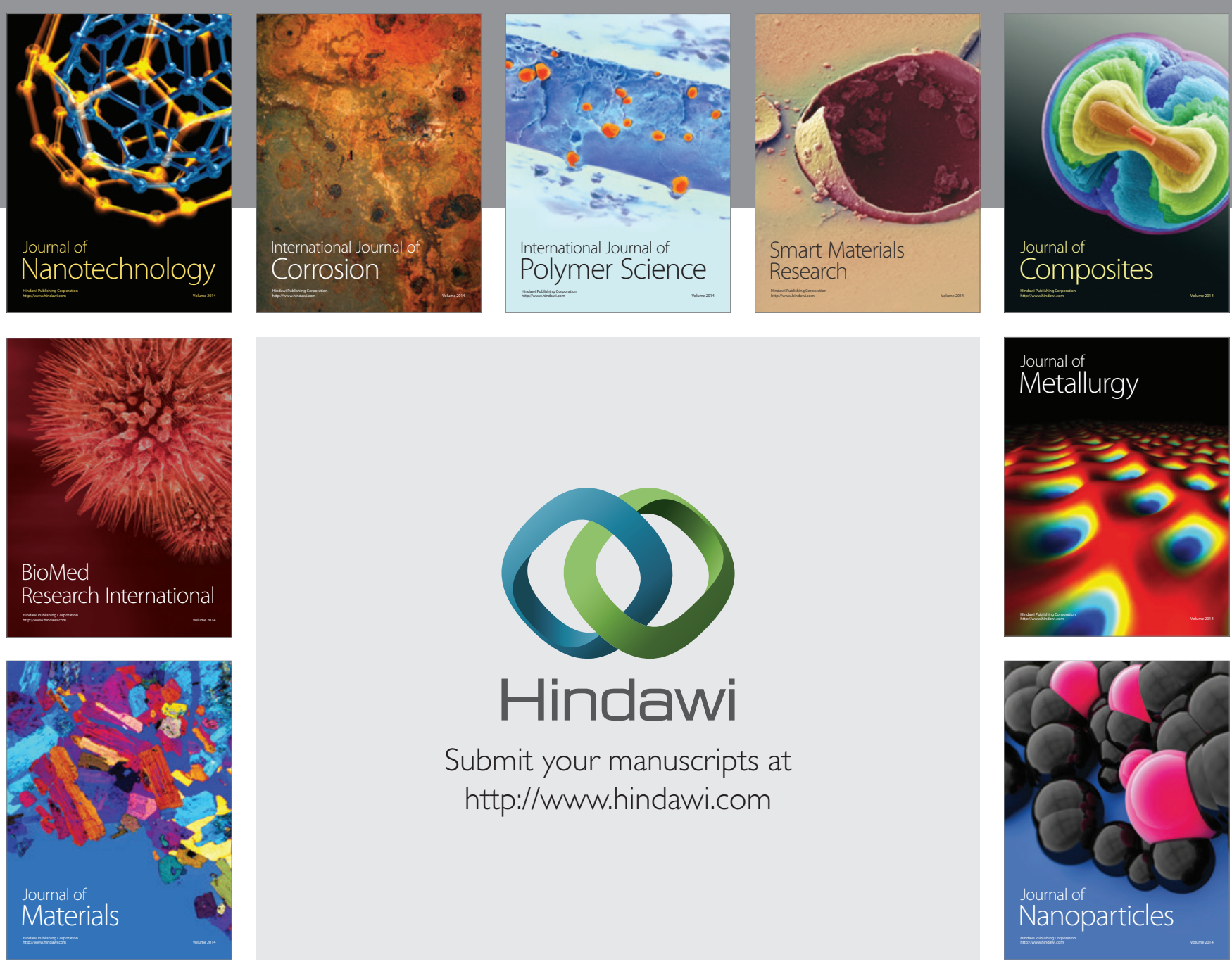

Submit your manuscripts at http://www.hindawi.com
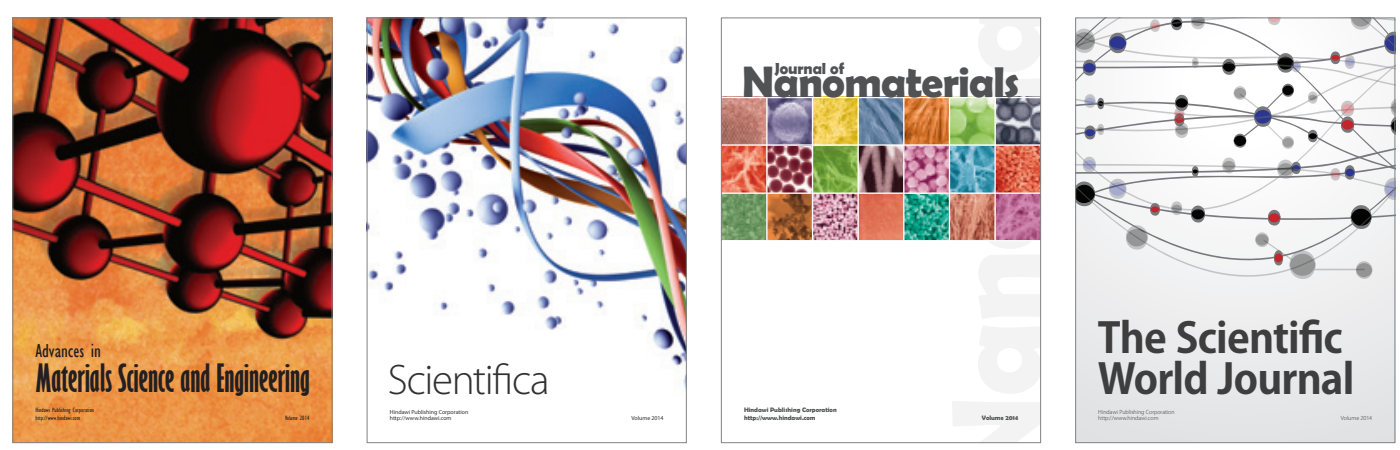

\section{The Scientific World Journal}
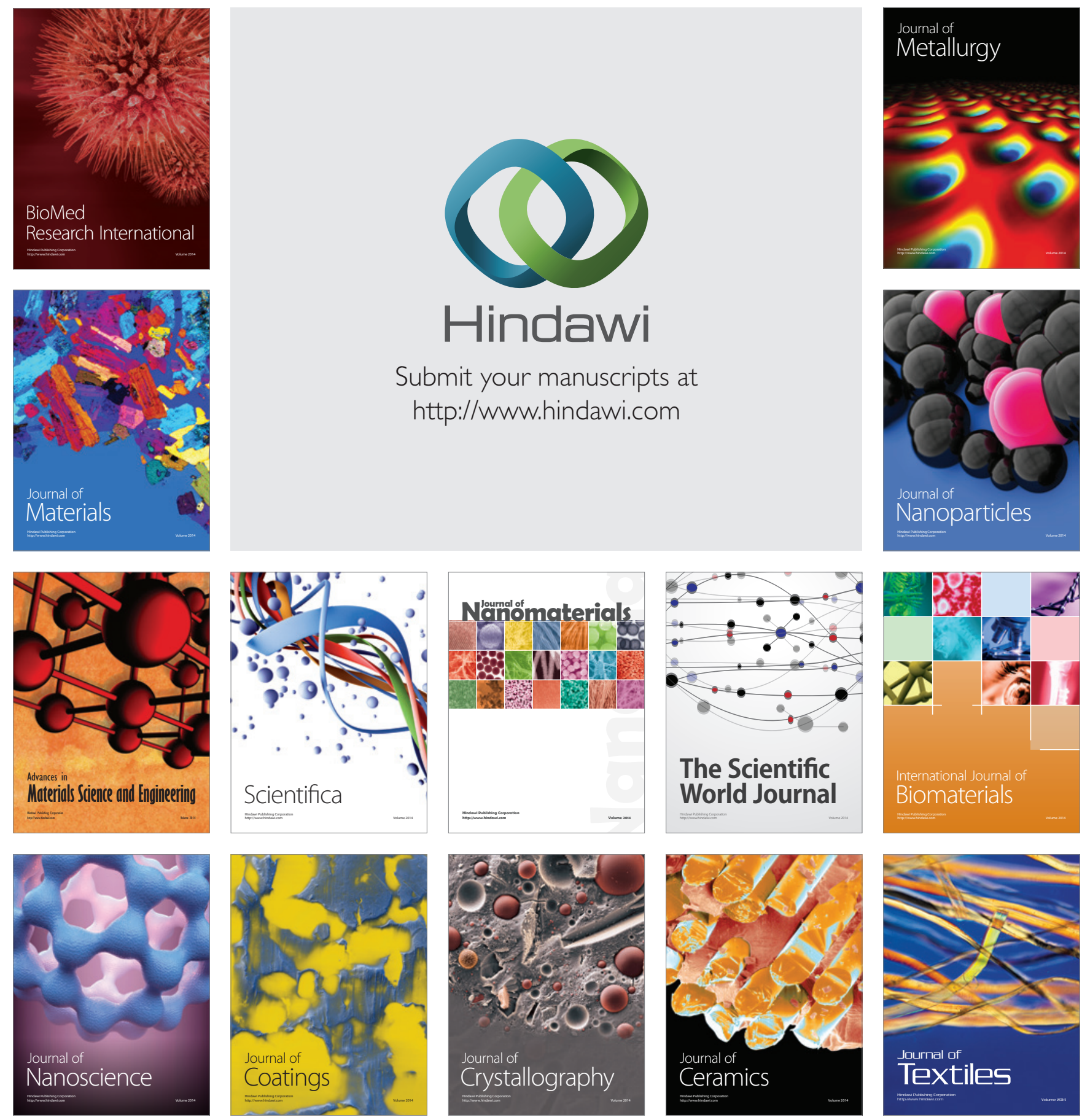